\title{
Más allá de la «matrícula viva». La movilidad del alumnado y la gestión local de la escolarización en Cataluña
}

\author{
Sílvia Carrasco \\ Jordi Pàmies \\ Ábel Bereményi \\ Vicenç Casalta \\ Universitat Autònoma de Barcelona. Grup EMIGRA - CER Migracions \\ silvia.carrasco@uab.cat; jordi.pamies@uab.cat; abel.beremenyi@uab.cat; vcasalta@xtec.cat
}

\section{Resumen}

El aumento de la movilidad del alumnado de las etapas preuniversitarias y, en especial, en los niveles de enseñanza obligatoria, se ha considerado una de las problemáticas más destacadas de la última década en España. Los procesos de incorporación del alumnado con movilidad y su gestión se perciben y se tratan de forma diversa desde las administraciones autonómicas y municipales, como también desde los centros educativos. En este contexto, se han popularizado expresiones para definir esta movilidad, como "matrícula viva», aplicadas al alumnado que se mueve entre los centros educativos fuera del periodo oficial de preinscripción. Así, no se suele concebir la movilidad como un proceso estructuralmente vinculado a las dinámicas socioeconómicas actuales ni a los cambios en la estructura productiva y el mercado laboral, o a factores residenciales conectados o no con los procesos anteriores, sino más bien como un problema esencialmente relacionado con las migraciones internacionales y su gestión a nivel local.

Este artículo muestra parte de los resultados obtenidos en una investigación realizada en la provincia de Barcelona ${ }^{1}$ centrada en el alcance y las dinámicas de la movilidad del alumnado, las motivaciones y estrategias de las familias y las condiciones de escolarización desde la perspectiva de la gestión municipal. El análisis comparativo a partir de la explotación de datos existentes, las entrevistas con agentes clave de diversos niveles de las administraciones autonómica y local y los docentes y las familias involucradas en estos procesos de movilidad

1. El equipo ha realizado la investigación a partir de un convenio de la Oficina de Planificación del Ârea de Educación de la Diputación de Barcelona y la Universitat Autònoma de Barcelona a lo largo de 2009 y 2010. 
han permitido reconstruir las diferentes dimensiones subyacentes al fenómeno y poner de manifiesto la complejidad del mismo. Los resultados de este estudio, el primero realizado en España sobre la movilidad del alumnado y la gestión de su escolarización, permiten concluir que esta movilidad corresponde en gran medida a diversas estrategias adaptativas que incluyen también a la población de nacionalidad española, señalan claras diferencias y límites en las respuestas llevadas a cabo en la gestión local de la escolarización y sitúan su análisis en el debate de los derechos educativos.

Palabras clave: estrategia familiar; administración local; derecho a la educación.

\section{Abstract: Beyond 'live enrolment': Student mobility and local management of schooling in Catalonia}

The increase in student mobility in pre-university education, and especially within compulsory education, has been regarded as one of the most challenging problems in the last decade in Spain. Processes to incorporate students in mobility programmes and the management of their mobility are viewed and addressed differently by regional and local administrations as well as by schools. In this context, the expression "live enrolment" - meaning year-round enrolment - has been coined to define and label not only this type of mobility, but also the students who move. Therefore, mobility is not usually conceptualized as a process structurally linked to current social and economic dynamics, ongoing changes in the productive structure and the labour market, or residential factors related or not to the former processes, but rather as a problem essentially tied to international migrations and the local management of such migrations.

This paper presents the partial results of a project carried out in the province of Barcelona focussing on the scope and dynamics of student mobility, families' motivations and strategies, and conditions of schooling from the viewpoint of local management. A comparative analysis based on available data, interviews with key agents at different levels of the local and regional administration, as well as meetings with teachers and families involved in the mobility process have allowed us to reconstruct a variety of underlying dimensions of student mobility, while highlighting the complexity of this phenomenon. The findings of this study, which is the first one on this issue in Spain, led to the conclusion that student mobility is largely the result of diverse adaptive strategies that also include Spanish families. Moreover, clear differences and limits were found regarding local responses by the education authorities, thus pointing to the need to analyse this issue within the debates on education rights.

Keywords: family strategy; local administration; right to education.

\section{Sumario}

\section{Introducción Resultados}

La movilidad del alumnado: su problematización en la literatura internacional

Una reflexión final

Referencias bibliográficas

Metodología y muestra 


\section{Introducción}

Uno de los retos más importantes de los últimos años en la planificación educativa ha sido dar respuesta al aumento de la movilidad del alumnado de las etapas preuniversitarias y, en especial, dentro de la enseñanza obligatoria. Esta movilidad se ha atribuido en parte a las dinámicas migratorias y a los procesos de reagrupación familiar, pero también debe analizarse como efecto de las estrategias familiares relativas a los cambios económicos y a la situación del mercado laboral o el acceso a la vivienda, sin dejar de explorar el impacto de factores específicamente educativos, como las diversas estrategias de escolarización de las familias.

Este fenómeno, que se conoce globalmente - y popularmente - en Cataluña como "matrícula viva», afecta de manera especial a los municipios de la provincia de Barcelona, ubicados en una estructura reticular que ha sufrido una urbanización progresiva de las zonas rurales paralela a la pérdida de población del núcleo central de la Ciudad Condal. Esta conurbación constituye un área metropolitana con distintas coronas cuya denominación incluye el territorio de la región metropolitana de Barcelona formada por ocho comarcas (Barcelonès, Vallès Occidental, Vallès Oriental, Maresme, Garraf, Alt Penedès, Anoia y Baix Llobregat) en las que se concentra la mayor parte de la población, casi 5 millones de habitantes sobre los aproximadamente 7,5 totales de la comunidad. Se trata también del territorio donde se localizan los mayores desplazamientos internos en términos de movilidad (cambios de residencia, movilidad cotidiana y flujos de población procedente del resto del Estado y del extranjero).

Precisamente, en el año 2008, en algunos de estos municipios, se produjo la llegada no prevista y muy numerosa de niños y jóvenes en edad escolar. Se acusó entonces a las administraciones de falta de planificación de las plazas escolares estableciendo una supuesta capacidad de previsión relacionada con la resolución de expedientes de solicitud de reagrupación familiar, como si esto hubiera sido el desencadenante de la situación creada. Todo ello se vio inevitablemente mezclado con las demandas no satisfechas de adjudicación de plazas escolares y las consiguientes protestas por parte de las familias, así como los debates locales entre el profesorado y los responsables educativos sobre el aumento de ratios o la apertura de líneas nuevas en los centros. Se volvieron a disparar los tópicos y los rumores sobre la alta movilidad del alumnado extranjero, sus procedencias y su ubicación en algunos centros, así como las supuestas consecuencias negativas acarreadas, alimentados por la competencia y las estrategias y las aspiraciones sociales y académicas de las familias.

Sin embargo, la inexistencia de datos empíricos contrastados impedía conocer el alcance real de la movilidad del alumnado en Cataluña y en los municipios de la provincia de Barcelona. Esta investigación pretende subsanar en parte dicha situación y, con la finalidad de conocer las motivaciones y los patrones de movilidad, asentamiento y escolarización por colectivos e identificar variables derivadas de la coyuntura económica de recesión, plantea la comparación de la situación de los municipios en la provincia — las distintas dinámicas locales- 
con la situación en Cataluña. Su objetivo ha sido conocer los movimientos del alumnado en la provincia desde fuera del sistema educativo de Cataluña (es decir, desde los que se trasladan desde otras comunidades y desde el extranjero) y también los movimientos internos entre municipios, prestando una especial atención a las prácticas y a los modelos de gestión de la movilidad a nivel municipal, con el fin de identificar experiencias de éxito y realizar propuestas de mejora y de coordinación a nivel de las administraciones locales.

El estudio ha intentado contemplar el alcance de esta movilidad desde una triple perspectiva:

1) Las dinámicas de la movilidad del alumnado y las distintas estrategias y motivaciones familiares que comportan cambios de centro educativo de los hijos y las hijas a lo largo del curso y en distintos momentos.

2) Las dimensiones del proceso de adjudicación de plazas escolares y las condiciones para la escolarización desde el análisis del marco normativo existente y de la gestión municipal.

3) El impacto de la movilidad en el alumnado afectado por el proceso.

Estas perspectivas permiten profundizar en el estudio de las condiciones de escolarización del alumnado en contextos de creciente y compleja diversidad sociocultural, objetivo central del grupo de investigación EMIGRA.

A la luz de las aportaciones más relevantes de la literatura de investigación sobre la movilidad del alumnado y a partir de la explotación de los datos disponibles, a menudo dispersos y de difícil comparación, en este articulo exponemos los resultados obtenidos desde las dos primeras perspectivas, centrándonos en las tendencias de la movilidad del alumnado en Cataluña y la gestión de la movilidad en el ámbito municipal.

\section{La movilidad del alumnado: su problematización en la literatura internacional}

La literatura de investigación sobre movilidad del alumnado es relativamente reciente y escasa, y prácticamente no existen precedentes en el Estado espa$\tilde{n o l}^{2}$. Una revisión de la literatura producida en este campo revela una mayor producción en sociedades con mayores niveles de movilidad, aunque las con-

2. El único trabajo realizado con anterioridad en la ciudad de Barcelona fue el estudio dirigido por S. CARRASCO (2003), Immigració i diversitat sociocultural a les escoles de Barcelona: Estudi sobre l'origen sociocultural $i$ la concentració escolar als centres públics municipals i de Ciutat Vella, que se realizó en el marco del primer Projecte Educatiu de Ciutat, con datos tomados entre 1998 y 2000. En este proyecto se incluyó un breve análisis de la movilidad interescolar (entre distintos cursos académicos) y de la movilidad irregular (o "matrícula viva») y se constató la existencia de tal fenómeno en todas las etapas educativas, incluso desde la etapa $0-3$, por parte principalmente de familias de nacionalidad española, hacia las escoles bressol municipales, que gozaban de gran prestigio, en cuanto había vacantes en ellas. Sin embargo, en aquel momento, la inmigración de familias con hijos e hijas en edad escolar y las primeras reagrupaciones familiares daban cuenta de la mayor parte de las incorporaciones escolares una vez iniciado el curso académico. 
tribuciones generalmente se han centrado en estudios de caso o bien responden a prospecciones de carácter extensivo resultado de encargos de las administraciones locales, en una línea similar a la realizada en la primera fase del estudio presentado en este artículo. Los trabajos existentes plantean fundamentalmente interrogantes sobre los tipos, las causas y la incidencia de la movilidad del alumnado, el impacto de los desplazamientos sobre el aprendizaje y la relación entre movilidad y precarización socioeconómica.

Algunos trabajos, realizados principalmente en la ciudad de Londres y en otras áreas de Inglaterra, plantean estas cuestiones con detalle. Así, el estudio de Gibbons y Telhaj (2007) aborda la relación entre movilidad y rendimiento académico y pone en evidencia que, aunque una mayor movilidad tiende a tener efectos negativos en el aprendizaje, esta no es la causa principal del bajo rendimiento en los alumnos afectados por ella. Gibbons y Telhaj (2007) proponían que las escuelas con alta movilidad deberían obtener mayores recursos por razones de equidad interescolar, en la medida en que la movilidad se convierte en un buen indicador de la existencia de alumnado con riesgo de bajo rendimiento por factores globales de contexto sociocultural. Informes como el Breaking Point (Association of London Government, 2005), desarrollado en 67 escuelas de los distritos de Hackney y Lambeth en Londres, muestra que la movilidad no está uniformemente distribuida entre escuelas y Local Education Authorities (LEA, o zonas escolares). A similares resultados llega el estudio de la Office for Standards in Education (2002) llevado a cabo por el Ministerio de Educación de Inglaterra y Gales y que analiza la movilidad en 3.300 escuelas primarias y en 1.000 centros de secundaria. El trabajo constata que las escuelas con los mayores niveles de movilidad tienden a ser precisamente aquellas que escolarizan al alumnado de familias de rentas más bajas, mientras que el trabajo de Dobson, Henthorne y Lynas (2000), por su parte, al examinar la naturaleza y las causas de la movilidad del alumnado en seis zonas escolares descubre que las migraciones y las rupturas familiares son los factores principales asociados a la movilidad del alumnado en su muestra.

Aspirando a comprender los efectos distintos de la movilidad, Hanusheck et al. (2004) recuerda y cuestiona la hipótesis ciertamente formalista de Thiebaut según la cual la movilidad producida por razones de elección de centro puede tener un impacto positivo en el rendimiento académico del alumnado. En cambio, el alumnado que ha cambiado de escuela desde una distancia mayor debido a un reasentamiento familiar, puede encontrar mayores dificultades de ajuste a la nueva escuela, a causa de otros ajustes vitales que debe realizar simultáneamente. Esta hipótesis clásica infiere, por lo tanto, que el alumnado que llega al inicio del curso tiene más probabilidades de haberse desplazado por razones de elección de escuela, en el periodo ordinario, cuando es más fácil la integración en el nuevo entorno, mientras que las llegadas a medio curso se deben con mayor probabilidad a cambios vitales inesperados y, también probablemente, más difíciles de asumir.

En los EEUU, la movilidad se ha asociado tradicionalmente a conceptos altamente valorados como la libertad, las oportunidades y la capacidad 
emprendedora. Sin embargo, las circunstancias que envuelven los cambios de residencia y las razones de los mismos producen profundas diferencias en cómo afectan a las familias y, en especial, a los menores. Además, los conceptos de movilidad residencial (cambios de residencia frecuentes) y de movilidad escolar (cambios frecuentes de escuela no estructurales) se solapan de forma significativa. Las actas del simposio organizado por Rumberger en 2010 y que reunió a un amplio conjunto de investigadores que habían abordado la cuestión del alumnado afectado por la movilidad constituyen un material de referencia en este campo en EEUU actualmente. En las conclusiones, se plantea que los datos disponibles hacen invisible hasta cierto punto el fenómeno en la medida en que no permiten reconstruirlo con facilidad y de forma longitudinal. Pero, según señalan otros autores, el alumnado con mayores niveles de movilidad es el que pertenece a minorías y a familias de rentas bajas, aunque aducen que es difícil identificar los motivos de los cambios de escuela. Un estudio realizado en Carolina del Norte, Florida y Nueva York (Hanushek et al., 2004) halló una mayor estabilidad entre alumnos blancos y asiáticos, y una menor permanencia entre alumnos hispanos y afroamericanos, aunque los afectados por la movilidad tendían a experimentar muchos cambios a lo largo del curso (con lo cual acumulaban experiencias de movilidad) y procedían de rentas bajas. Estos resultaban ser los indicadores más relevantes. A similares conclusiones llega Shaft (2006) a través de un estudio realizado en la ciudad de Nueva York al poner de relieve que las familias de rentas bajas tienden a moverse con mayor frecuencia pero no a grandes distancias, mientras que los estudiantes de minorías son los más afectados por la movilidad, en la medida en que están sobrerrepresentados en aquella categoría. Estos resultados no hacen más que confirmar el fenómeno señalado por Nakagawa et al. (2002), que reconsideran la tradicional visión positiva de la movilidad en los EEUU a través de lo que denominan el city migrant dilemma, o «dilema del migrante urbano». Este dilema parte de considerar las estrategias desarrolladas por las familias en contextos urbanos cada vez más hostiles y en procesos de precarización laboral creciente, que hacen inviable el arraigo en un lugar específico de la ciudad, aunque pueden llegar a conocer los diferentes entornos y dinámicas de ella, lo cual permite el desarrollo de una itinerancia en busca de empleo que, finalmente, provoca la movilidad escolar de sus hijos e hijas dentro de la misma población o hacia entornos cercanos.

A partir de estas aportaciones, el estudio realizado se plantea contribuir a llenar el vacío existente en la investigación del estado sobre movilidad del alumnado por medio de un abordaje cuantitativo y cualitativo que permita conocer su alcance y sus características, así como las respuestas organizativas y de gestión que se han desarrollado en Cataluña.

\section{Metodología y muestra}

La investigación se ha centrado en el alumnado escolarizado en los centros públicos y concertados de Cataluña y de la provincia de Barcelona desde el 
inicio de la escolarización en preescolar (P3) hasta la finalización de la educación secundaria obligatoria (cuarto de ESO), etapas para las que se dispone de datos relacionados con el fenómeno de la movilidad en las diversas fuentes consultadas (municipios y Departamento de Educación).

El trabajo realizado ha seguido dos fases diferenciadas. Por un lado, se ha llevado a cabo una fase extensiva en la que se ha trabajado con datos disponibles en tres niveles de desagregación ${ }^{3}$ : Cataluña, la provincia de Barcelona y una muestra de doce municipios. En esta fase, el objetivo ha sido conocer las dinámicas y las tendencias de la movilidad del alumnado por colectivos, así como las causas que comportan cambios de centro educativo a lo largo del curso y en distintos momentos del mismo. La selección de estos doce municipios se ha basado en tres criterios, acordados por el equipo de investigación y los responsables técnicos de la Oficina de Planificación de la Diputación de Barcelona: tamaño del municipio (pequeño, mediano, grande), presencia de población extranjera de distintas áreas de origen y representación comarcal (incluyendo al menos un municipio de cada comarca de la provincia).

En la fase extensiva, se ha trabajado en los siguientes municipios:

1. Municipios pequeños: Carme (Anoia), Sant Quintí de Mediona (Alt Penedès), Olivella (Garraf) y Calaf (Anoia).

2. Municipios medios: Canovelles (Vallès Oriental), Berga (Berguedà), Calella (Maresme) y Martorell (Baix Llobregat).

3. Municipios grandes: Manlleu (Osona), Rubí (Vallès Occidental), Manresa (Bages), Santa Coloma de Gramenet (Barcelonès).

Por otro lado, la investigación ha desarrollado una fase intensiva, profundizando en el estudio de la movilidad del alumnado y su tratamiento en tres municipios de distinto tamaño, composición y ubicación en el territorio. En este nivel, se han recopilado datos del contexto local sobre dinámicas sociodemográficas, económicas y educativas específicas, se ha entrevistado a una selección de informantes diversos entre los agentes implicados en el fenómeno (técnicos y políticos municipales y comarcales, responsables políticos supramunicipales, miembros de equipos directivos de centros educativos, profesorado y familias) y se ha aplicado una batería de técnicas de investigación cuantitativa y cualitativa (reconstrucción y primera explotación de datos, análisis de documentos, visitas a los municipios, a las oficinas municipales y a los centros escolares).

3. Se ha construido una base de datos de trabajo a partir de distintos ficheros de datos de cada una de las fuentes siguientes: Departament d'Educació (diversos servicios y unidades), Diputació de Barcelona (unidad de padrón), oficinas municipales de escolarización, ayuntamientos de los municipios de la muestra, consejos comarcales y centros educativos. La falta de criterios de registro comparables y la ausencia de series temporales presentan, por el momento, serias limitaciones en las posibilidades de explotación de los datos cuantitativos más allá de ofrecer un tratamiento descriptivo. 
En la fase intensiva se ha trabajado en tres municipios de tres comarcas distintas: uno de tamaño grande, uno de tamaño mediano y uno de tamaño pequeño.

Para hacer un abordaje completo y contextualizado de la movilidad del alumnado en Cataluña y la provincia de Barcelona, el estudio se ha planteado distinguir, reconstruir y analizar la incidencia de procesos diversos que la representan. Para ello, se han tratado, de forma diferenciada y comparativa, tres fenómenos distintos: las altas y bajas fuera de plazo, las altas y bajas de la llamada matrícula viva y, complementariamente, las altas y bajas en los periodos ordinarios de preinscripción y matriculación. Estas tres situaciones se han definido como sigue:

- Matrícula fuera de plazo (a partir de ahora, FT —en catalán, fora de termi$n i-)$ : es la matrícula que realiza el alumnado que no ha seguido el proceso de preinscripción ordinario marcado por el calendario, pero que solicita plaza escolar desde la finalización de este calendario de preinscripción y matriculación hasta el 30 de septiembre. Las bajas son las que tienen lugar en el mismo periodo 4 .

- Matrícula viva (a partir de ahora, MV): es la matrícula que realiza el alumnado que no ha seguido el proceso de preinscripción ordinario marcado por el calendario y que solicita plaza escolar después del 30 de septiembre y a lo largo del curso. Las bajas de MV son las que tienen lugar en el mismo periodo.

- Matrícula ordinaria: es la matrícula que realiza el alumnado que ha seguido el proceso de preinscripción ordinario marcado por el calendario escolar del Departamento de Educación de la Generalitat de Catalunya.

Para proporcionar una primera visión de los resultados obtenidos, en este artículo se incluye, en primer lugar, un análisis de las tendencias y dinámicas de la movilidad del alumnado en Cataluña y la provincia de Barcelona a partir del segundo de estos fenómenos, la "matrícula viva", limitándonos en este caso a las altas que se producen. En segundo lugar, nos centraremos en el análisis de la diversidad de respuestas que se han producido para llevar a cabo la gestión de la escolarización a nivel local, señalando los límites a los que esta se enfrenta.

\section{Resultados}

\section{La movilidad del alumnado en Cataluña y Barcelona: tendencias y dinámicas}

En el último decenio, la población escolar en el sistema educativo de Cataluña ha seguido un promedio anual de crecimiento del $3 \%$, aunque con una intensidad variable desde el 1\% (2001-2002) hasta el 4\% (2007-2008). Una parte de este crecimiento ha sido resultado del aumento del alumnado en

4. La inexistencia de orientaciones sistemáticas alrededor de este fenómeno conlleva algunas diferencias en las formas de registro de la movilidad a nivel local y autonómico. Por ejemplo, en la delimitación clara y general de las categorías MV y FT al principio de curso. 
Gráfica 1. Evolución global de la MV en Cataluña. Cursos 2007-2008 y 2009-2010

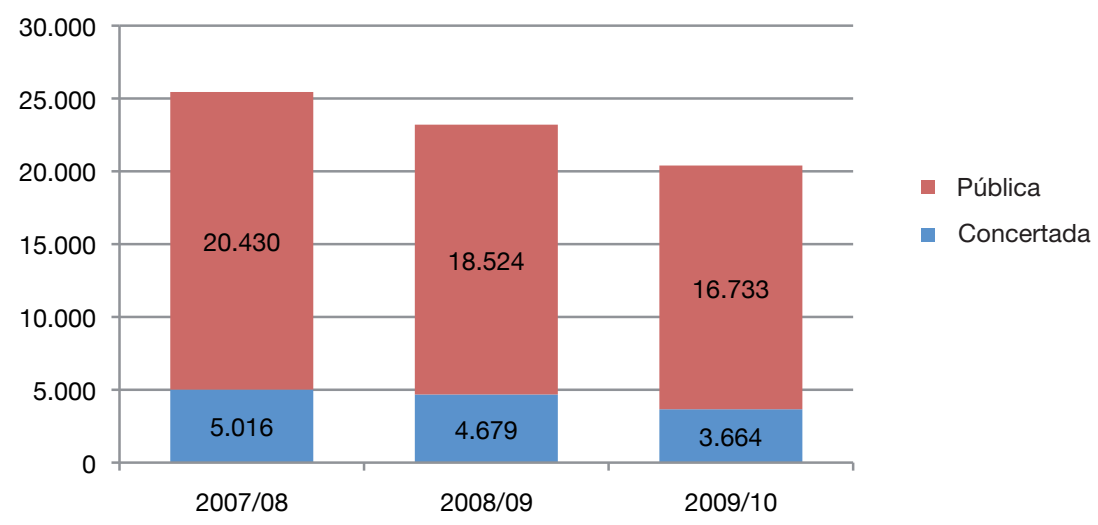

Fuente: elaboración propia a partir de los datos del Departament d’Educació de la Generalitat de Catalunya.

periodo de matriculación ordinaria y FT, mientras que otra se ha debido a las incorporaciones en periodo de MV. Según los datos obtenidos, entre 20062007 y 2009-2010 el volumen de las llegadas en periodo de MV para el total de Cataluña alcanzó su máximo en el curso 2007-2008, con 25.446 casos, y disminuyó en los cursos posteriores, con 23.203 (2008-2009) y 20.397 (20092010) casos. Unas cifras que apuntan a una reducción del $25 \%$ entre 2007 2008 y 2009-2010. Esta primera aproximación cuantitativa a la movilidad del alumnado en España ya muestra, a pesar de sus limitaciones y en un primer tratamiento descriptivo como el realizado para este artículo, la existencia de una representación distorsionada y simplificada de la llamada «matrícula viva» como un fenómeno principalmente asociado a las migraciones internacionales.

La incorporación del alumnado de MV a los centros públicos y concertados ha sido desigual. Se ha situado en una relación aproximada de $80 \%$ a $20 \%$. Si comparamos estas cifras con las proporciones globales de centros públicos y centros concertados en las etapas correspondientes al conjunto que va de P3 a cuarto de ESO, constatamos que en las escuelas públicas se ha escolarizado una cantidad más elevada de alumnado de MV del que le correspondería en proporción a las matrículas ordinarias. Así, en el curso 2007-2008, los centros concertados tan solo gestionaban el $18 \%$ de la MV, la mitad de la que les correspondería por proporción de matrículas ordinarias. A medida que se reduce la escala de análisis del fenómeno, se evidencian mayores desequilibrios en el territorio.

La incorporación de este alumnado en las cuatro provincias catalanas también se produce de forma desigual. Mientras que las escuelas de Barcelona acogen al 73\% de estos niños y jóvenes, las de Tarragona lo hacen en un $11 \%$, seguidas por las de Girona, con el 10\%, y las de Lleida, con el $6 \%$. En 
Gráfica 2. MV en Cataluña, por provincias, etapas y titularidades

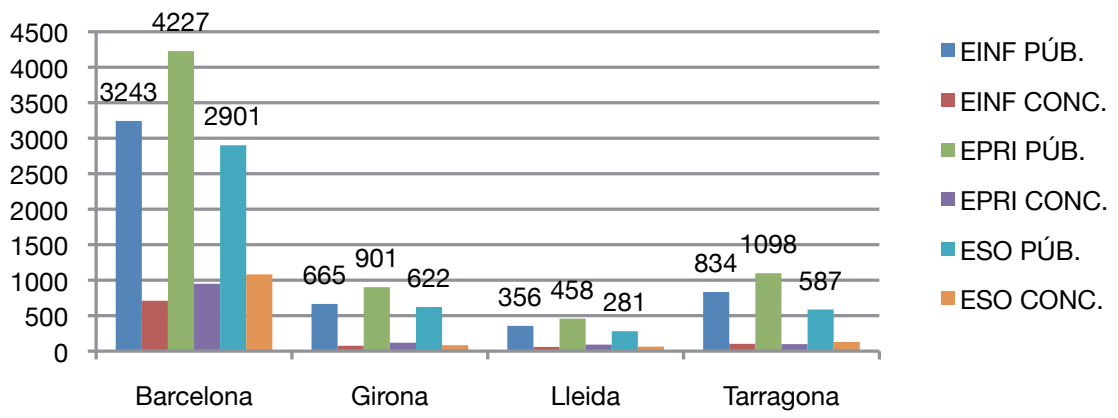

Fuente: elaboración propia a partir de los datos del Departament d’Educació de la Generalitat de Catalunya.

la gráfica 2, que representa las cifras absolutas de MV por provincia, etapa y titularidad, se constata que son los centros públicos, en las tres etapas, y en especial en la provincia de Barcelona, los que más alumnado de MV escolarizan. Ahora bien, el peso de la MV sobre la población escolar total en cada provincia es superior en todas las etapas en Tarragona (a excepción de la primaria concertada) seguida de Girona y Lleida. En Barcelona, tan sólo se iguala la proporción del resto de provincias en los centros públicos de la etapa de ESO, donde representa una proporción del 3\% del total del alumnado.

La gráfica 3 muestra la proporción de MV total de Cataluña por etapa y titularidad. Se puede observar que la distribución de MV por etapas es bastante pareja a la del alumnado total $(31 \%, 40 \%, 29 \%)$. En cambio, la distribución

Gráfica 3. Distribución de la MV por etapas y tutularidades en Cataluña. Curso 2009-2010

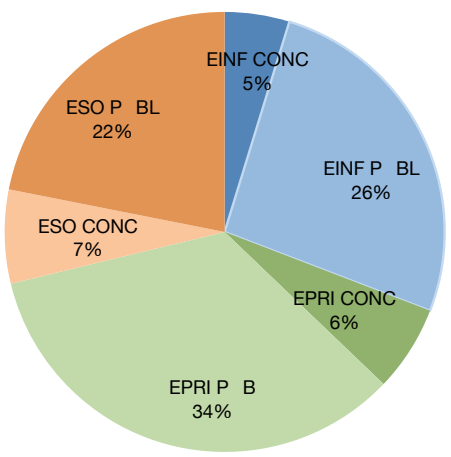

Fuente: elaboración propia a partir de los datos del Departament d’Educació de la Generalitat de Catalunya. 
Gráfica 4. Distribución de la MV por meses en Cataluña. Curso 2009-2010

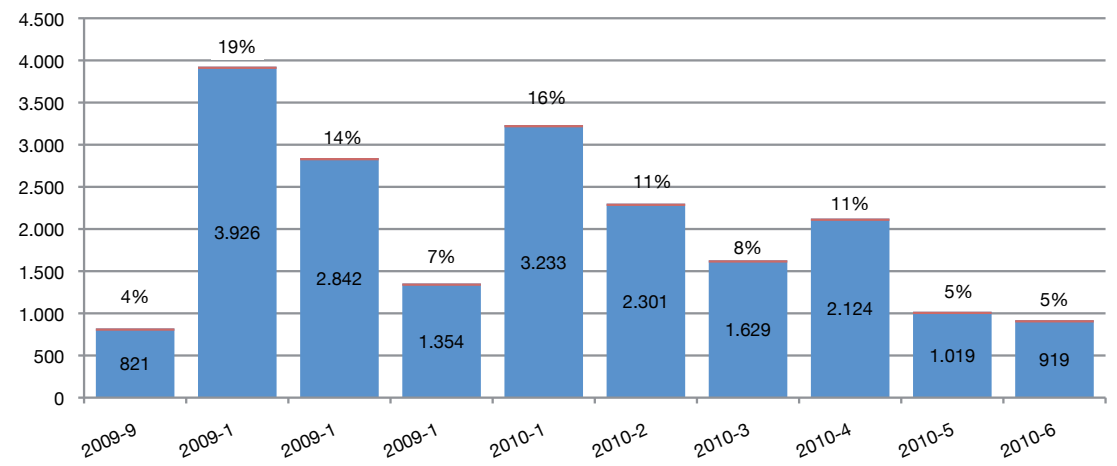

Fuente: elaboración propia a partir de los datos del Departament d’Educació de la Generalitat de Catalunya.

de MV por titularidad presenta desproporciones importantes: en todas las etapas, la MV en los centros concertados es menor a la que se produce en los centros públicos. Por ejemplo, esta incidencia más baja en la educación infantil de los centros concertados se traduce en un 1\%, mientras que el $25 \%$ de la distribución que corresponde a los centros públicos se traduce en un 3\%.

La gráfica 4 detalla los movimientos mensuales de la MV a lo largo del curso académico 2009-2010. Las matrículas de septiembre son, de hecho, las que tienen una fecha de registro posterior al 1 de octubre, por tanto, las proporciones reflejan la MV entre octubre y junio y desestiman las matrículas FT, que son las que realmente aportan la mayor parte de la matrícula realizada fuera del periodo ordinario de matriculación. Los dos picos de MV se producen en los meses de octubre y enero. El primero incluye solicitudes iniciadas en los meses anteriores, pero también nuevas demandas. Las MV de enero en gran parte corresponden al alumnado que se incorpora al sistema educativo desde fuera del estado, principalmente procedente de países latinoamericanos, con un calendario escolar que finaliza el curso en diciembre y comienza las vacaciones en enero. El tercer mes más activo en el 2009-2010 fue noviembre. Es interesante observar la intensidad de MV en los meses de mayo y junio, que de alguna manera podría hacer cuestionar ciertas prácticas en la ESO que recomiendan no matricular al alumnado recién llegado a partir de finales de mayo.

Resulta importante observar que en Cataluña, durante el curso 2009-2010, la distribución global del alumnado por nacionalidad muestra que mientras el 58\% de la MV se produce con alumnado de nacionalidad extranjera, el alumnado de nacionalidad española llega a ser su protagonista en el $42 \%$ de los casos. La participación dentro del fenómeno presenta, según estos datos, dos situaciones diferenciadas en los extremos: en los centros concertados y en la educación infantil, el alumnado de nacionalidad española supera en volumen de MV al alumnado de nacionalidad extranjera, mientras que, en los centros 
Gráfica 5. Distribución de la MV por nacionalidades, etapas escolares y titularidades en Cataluña. Curso 2009-2010

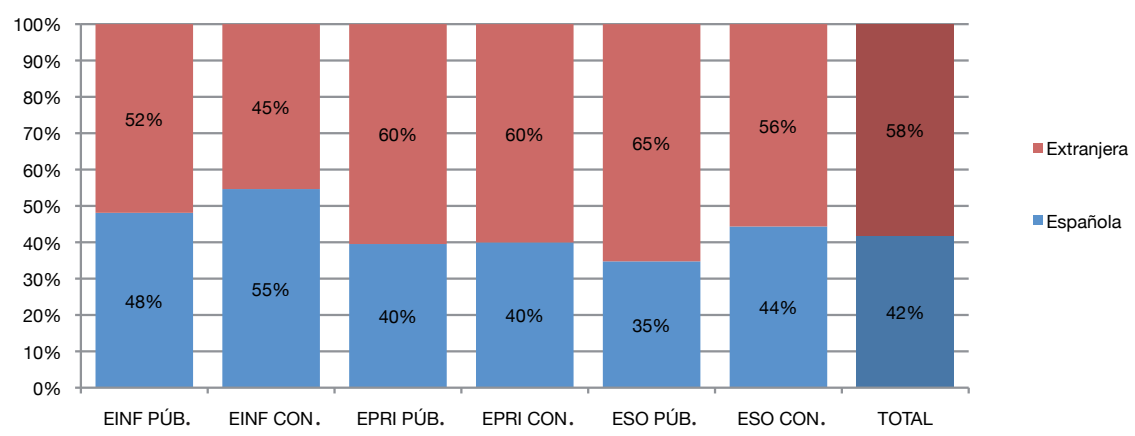

Fuente: elaboración propia a partir de los datos del Departament d'Educació de la Generalitat de Catalunya.

públicos y dentro de la ESO, el alumnado de nacionalidad extranjera representa el $65 \%$ de la MV.

El gráfico nos muestra como, en Cataluña, alrededor del $40 \%$ de la MV corresponde a alumnado de nacionalidad española en todas las etapas educativas, aunque existan entre ellas ligeras variaciones — tendencia que se mantiene en la provincia de Barcelona. Por nacionalidades, el alumnado de nacionalidad marroquí ocupa la segunda posición, y un conjunto diverso de nacionalidades (de Asia y América Latina) ocupa las posiciones siguientes según su distribución en el territorio, tanto en los centros concertados como en los centros públicos. Si contemplamos la distribución de la MV por nacionalidades y sus causas, como

Gráfica 6. Alumnado MV por nacionalidades en Cataluña. Curso 2009-2010

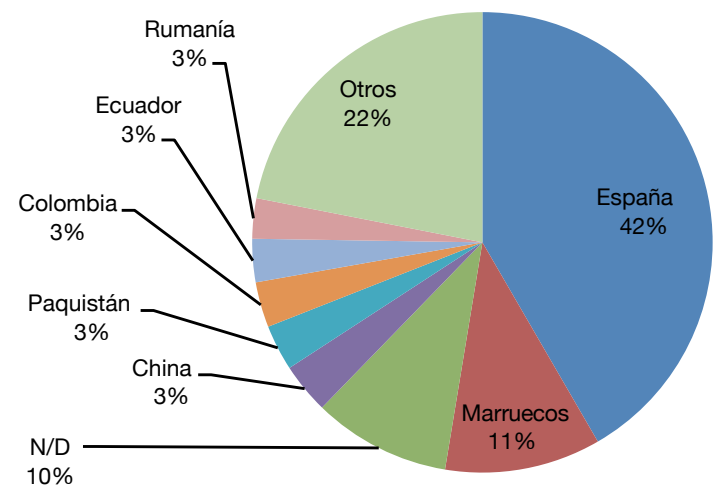

Fuente: elaboración propia a partir de los datos del Departament d’Educació de la Generalitat de Catalunya. 
Gráfica 7. Alumnado MV por nacionalidades y etapas en Cataluña. Curso 2009-2010 MV por nacionalidad en EINF, Cataluña 2009/2010

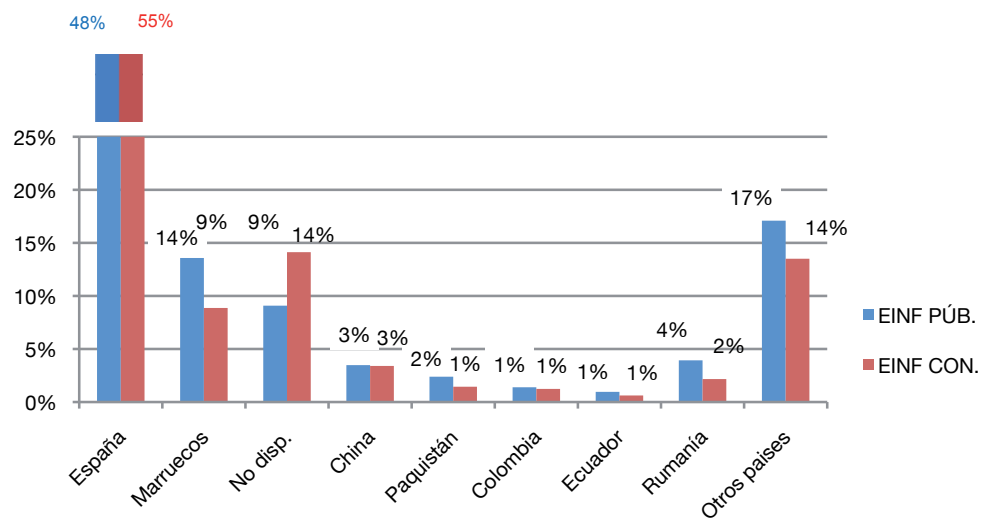

MV por nacionalidad en EPRI, Cataluña 2009/2010

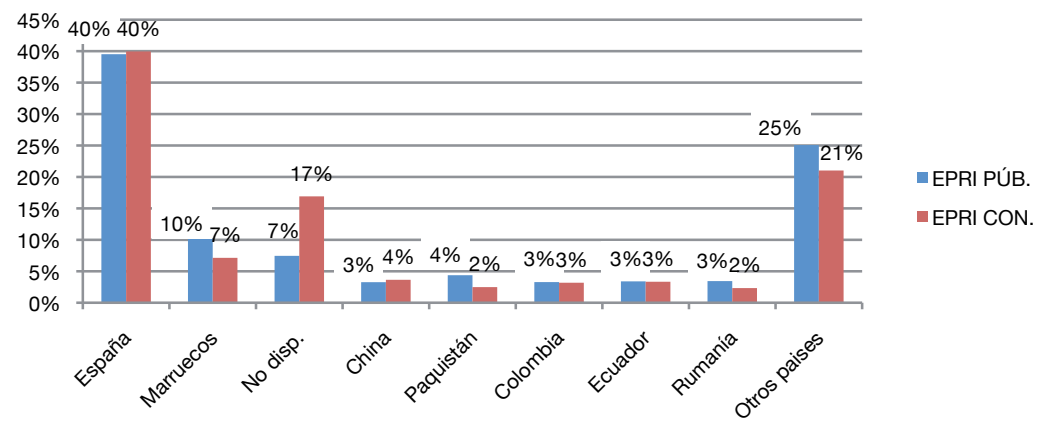

MV por nacionalidad en ESO, Cataluña 2009/2010

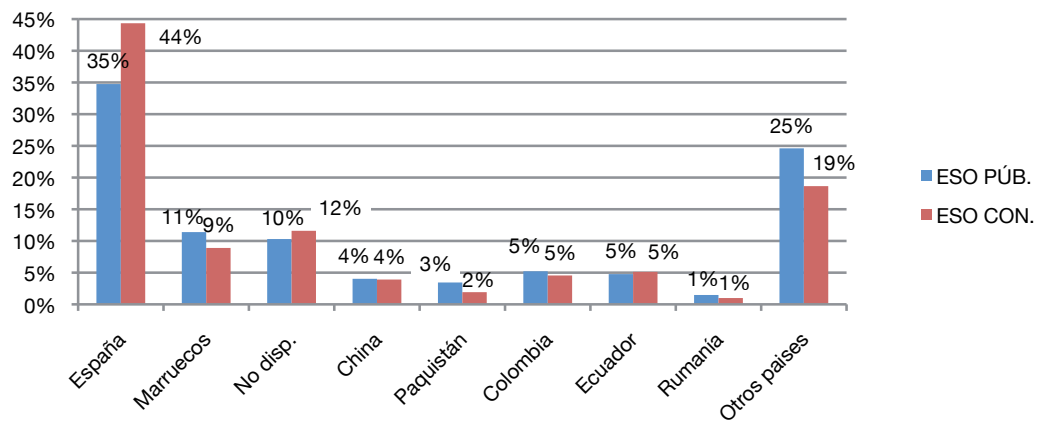

Fuente: elaboración propia a partir de los datos del Departament d’Educació de la Generalitat de Catalunya. 
Gráfica 8. Motivo de solicitud de MV por titularidad

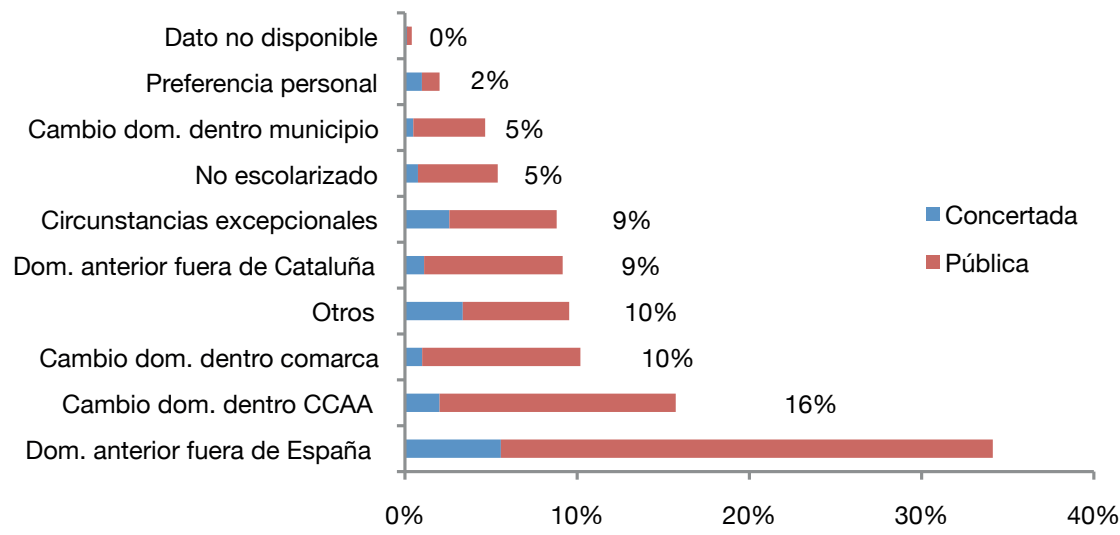

Fuente: elaboración propia a partir de los datos del Departament d’Educació de la Generalitat de Catalunya.

veremos en la tabla 1 , observaremos los patrones diferenciados que los diversos grupos aplican a la hora de cambiar de domicilio y/o de centro educativo.

La distribución de la MV por nacionalidades, etapas y titularidades presenta algunas variaciones a destacar. Mientras la incorporación del alumnado de nacionalidad española, el alumnado del conjunto de nacionalidades latinoamericanas y el alumnado rumano produce un volumen de MV similar en los centros públicos y en los centros concertados en las etapas de educación infantil y de educación primaria, el alumnado de nacionalidad marroquí y paquistaní contribuye más a la MV de los centros públicos. El alumnado de MV del que no tenemos datos de nacionalidad presenta una fuerte tendencia hacia los centros concertados.

El 44\% de la MV de ESO en los centros concertados y el 35\% de la MV de ESO en los centros públicos corresponde a alumnado de nacionalidad española. Estos datos podrían mostrar la tendencia a permanecer a la espera de la oferta de plazas de los centros concertados como parte de la estrategia de escolarización de un sector importante de las familias catalanas. El alumnado que produce MV de nacionalidades china, colombiana, ecuatoriana y rumana acuden en proporciones similares a los centros públicos y a los centros concertados en la etapa de ESO. En cambio, el alumnado de nacionalidad marroquí y paquistaní, así como el resto de alumnado extranjero, tienden a contribuir mucho más a la MV de los centros públicos en la etapa de ESO. Como consecuencia de estas diferencias, ante las que parece que las $\mathrm{OME}^{5}$ tienen poca

5. Las oficinas municipales de escolarización (OME) nacieron por el Decreto 252/2004, de 1 de abril, y tienen, entre otras finalidades, tal como se establece en el artículo 18.4: además de velar por el cumplimiento de la legalidad en los procesos de admisión del alumnado, "procurar una distribución equilibrada del alumnado de necesidades educativas específicas 
capacidad de corrección en términos globales, la diversidad de nacionalidades en los centros concertados es mucho menor que en los centros públicos: los centros concertados incorporaron 69 nacionalidades diversas para MV durante el curso 2009-2010, mientras que los centros públicos incorporaron 104.

A partir de los datos, podemos constatar que sólo el 34\% de las solicitudes corresponden a alumnado recién llegado del extranjero, con ligeras variaciones relativas por titularidad, siempre más alta en los centros públicos, y con total coincidencia entre el conjunto de Cataluña y el conjunto de la provincia de Barcelona. Ante la dificultad de interpretar motivos más frecuentes en los centros concertados («Otros», "Circunstancias excepcionales»), sí se puede afirmar un patrón de movilidad interna importante en los centros públicos, donde, tras el motivo más frecuente («Domicilio anterior fuera de España»), se observan movilidades dentro de Cataluña, desde el resto del Estado y dentro de la comarca. Hay que hacer notar que el motivo «Domicilio anterior fuera de Cataluña» es el segundo más frecuente de MV en los centros concertados de la provincia de Barcelona. En resumen, pues, se confirma que el $31 \%$ de la movilidad corresponde a cambios efectuados dentro del sistema educativo en Cataluña, con poca diferencia en conjunto con el 34\% de MV procedente del extranjero. A este $31 \%$ hay que añadir, probablemente, como cambios de centros dentro del sistema educativo en Cataluña, las categorías "Preferencia personal» $\mathrm{y}$ "Circunstancias excepcionales».

La tabla muestra con detalle la distribución de la MV por nacionalidades. Resulta relevante a la hora de identificar las estrategias y los patrones diferentes que los grupos pueden llevar a cabo a la hora de cambiar de domicilio y/o de centro educativo. Una parte del alumnado de MV acaba de llegar del extranjero con una mayor incidencia entre el alumnado de nacionalidad pakistaní, dominicana y colombiana. Los movimientos de alumnado de otras nacionalidades, en cambio, son más diversos. En especial, si contemplamos las tendencias de las tres nacionalidades de mayor presencia en Cataluña, constatamos que:

- Sólo el 41\% de los alumnos marroquíes son nuevas incorporaciones del extranjero, pero, en cambio, existe una alta movilidad dentro de la comarca y dentro de Cataluña.

- En el caso de los alumnos rumanos, sólo el 50\% procede de fuera del Estado español, con una proporción de hijos no escolarizados anteriormente (9\%). También se observa una cierta movilidad dentro del Estado (10\%), Cataluña $(8 \%)$ y el mismo municipio (8\%). Según estos datos, el alumnado de nacio-

que permita la integración, facilite la cohesión social y favorezca una calidad educativa adecuada para toda la población escolar [...]». Fueron concretadas más tarde en el Decreto 75/2007, del 27 de marzo, y a ellas también se hacía referencia en el artículo 48 de la Ley de educación 12/2009, de 10 de julio. Las primeras 12 OME se crearon en Badalona, Mataró, Terrassa, Vilanova i la Geltrú, Reus, Vic, Manlleu, Olot, Banyoles, Figueres, Cervera y la Seu d'Urgell, y entraron en funcionamiento durante el curso 2004-2005. En el curso siguiente, las OME se extendieron a 25 municipios más (Bonal, 2006) y, actualmente, el número de municipios con OME es de 64, según datos del Departament d'Ensenyament. 
nalidad rumana es el que presenta motivos más diversos de cambio de centro. - El alumnado ecuatoriano que llega directamente de fuera del Estado representa el 55\%. También se observa que existe una movilidad interna del alumnado de este colectivo nacional dentro de Cataluña (10\%) y del Estado (9\%).

El impacto local de la movilidad del alumnado presenta variaciones importantes que permiten entender también la diversidad de dinámicas y motivos y la capacidad de respuesta de cada municipio con relación a los recursos de que dispone en su entorno inmediato y en la red territorial de la que forma parte. Por ejemplo, algunos municipios pequeños, como en el caso estudiado de Sant Quintí de Mediona, con un sólo centro de educación infantil y primaria de titularidad pública, y con 17 alumnos de MV en un curso académico, las incorporaciones del alumnado a lo largo del curso escolar son proporcionalmente más numerosas que en otros municipios de mayores dimensiones como Santa Coloma de Gramenet, que, en el año 2009, contó con 504 alumnos matriculados después del inicio de curso y del periodo de FT. Al respecto, es necesario realizar dos consideraciones:

- La primera, y en referencia al impacto local: cuando, en el año 2008, se produjo un incremento importante del número de niños llegados a Cataluña fuera del periodo de matriculación ordinario fue en los municipios grandes y en especial en algunas ciudades, como en el caso que nos ocupa de Santa

Tabla 1. MV por motivos y nacionalidad en Cataluña. Curso 2009-2010

\begin{tabular}{|c|c|c|c|c|c|c|c|c|c|c|c|c|}
\hline NACIONALIDAD & 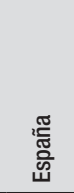 & 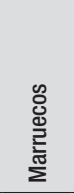 & 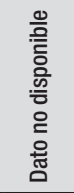 & $\begin{array}{l}\frac{\pi}{0} \\
\frac{\overline{0}}{\overline{0}} \\
\frac{0}{0}\end{array}$ & 䒿 & 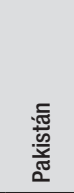 & $\begin{array}{l}\text { 흠 } \\
\text { 륨 }\end{array}$ & 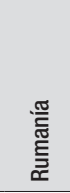 & 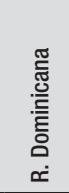 & 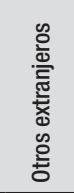 & $\begin{array}{l}\text { 읗 } \\
\text { 흐 } \\
\text { 힌 }\end{array}$ & क्ञّँ \\
\hline $\begin{array}{l}\text { Domicilio anterior fuera de } \\
\text { España }\end{array}$ & $9 \%$ & $41 \%$ & $22 \%$ & $69 \%$ & $61 \%$ & $81 \%$ & $55 \%$ & $50 \%$ & $74 \%$ & $63 \%$ & $34 \%$ & 6.476 \\
\hline $\begin{array}{l}\text { Cambio domicilio dentro de la } \\
\text { misma comunidad autónoma }\end{array}$ & $26 \%$ & $10 \%$ & $11 \%$ & $5 \%$ & $12 \%$ & $3 \%$ & $10 \%$ & $8 \%$ & $8 \%$ & $9 \%$ & $16 \%$ & 3.079 \\
\hline Cambio domicilio de comarca & $14 \%$ & $10 \%$ & $6 \%$ & $6 \%$ & $5 \%$ & $3 \%$ & $4 \%$ & $8 \%$ & $5 \%$ & $6 \%$ & $10 \%$ & 1.849 \\
\hline Otros & $13 \%$ & $9 \%$ & $15 \%$ & $4 \%$ & $4 \%$ & $2 \%$ & $6 \%$ & $5 \%$ & $2 \%$ & $4 \%$ & $9 \%$ & 1.788 \\
\hline $\begin{array}{l}\text { Domicilio anterior fuera } \\
\text { de Cataluña }\end{array}$ & $13 \%$ & $7 \%$ & $7 \%$ & $7 \%$ & $3 \%$ & $1 \%$ & $9 \%$ & $10 \%$ & $5 \%$ & $6 \%$ & $9 \%$ & 1.772 \\
\hline Circunstancias excepcionales & $13 \%$ & $8 \%$ & $9 \%$ & $6 \%$ & $5 \%$ & $2 \%$ & $9 \%$ & $5 \%$ & $2 \%$ & $5 \%$ & $9 \%$ & 1.683 \\
\hline No escolarizado & $4 \%$ & $10 \%$ & $12 \%$ & $1 \%$ & $6 \%$ & $5 \%$ & $2 \%$ & $9 \%$ & $2 \%$ & $4 \%$ & $5 \%$ & 1.016 \\
\hline $\begin{array}{l}\text { Cambio domicilio dentro } \\
\text { de municipio }\end{array}$ & $5 \%$ & $5 \%$ & $6 \%$ & $2 \%$ & $4 \%$ & $1 \%$ & $4 \%$ & $5 \%$ & $3 \%$ & $4 \%$ & $5 \%$ & 911 \\
\hline Preferencia personal & $3 \%$ & $1 \%$ & $7 \%$ & $1 \%$ & $0 \%$ & $0 \%$ & $1 \%$ & $0 \%$ & $0 \%$ & $0 \%$ & $2 \%$ & 392 \\
\hline Dato no disponible & $0 \%$ & $0 \%$ & $4 \%$ & $0 \%$ & $0 \%$ & $0 \%$ & $0 \%$ & $0 \%$ & $0 \%$ & $0 \%$ & $0 \%$ & 77 \\
\hline \multirow[t]{2}{*}{ Total \% } & $100 \%$ & $100 \%$ & $100 \%$ & $100 \%$ & $100 \%$ & $100 \%$ & $100 \%$ & $100 \%$ & $100 \%$ & $100 \%$ & $100 \%$ & 19.043 \\
\hline & 8.081 & 2.015 & 1.835 & 626 & 612 & 608 & 564 & 555 & 411 & 3.736 & & 19.043 \\
\hline
\end{tabular}

Fuente: elaboración propia a partir de los datos del Departament d'Educació de la Generalitat de Catalunya. 
Coloma, donde la situación fue más delicada y adquirió un carácter más mediático. La llegada de estos niños y niñas, no prevista, agravó problemáticas previas, derivadas de las características de la propia oferta existente de plazas escolares en el municipio y la competencia por las mismas.

- La segunda consideración nos lleva a cuestionar la existencia de patrones de movilidad y asentamiento asociados al tamaño del municipio. Tanto en los municipios pequeños, como en los medianos y en los grandes, las entrevistas realizadas nos han permitido certificar que el impacto diferencial que explicaría el fenómeno de la MV tiene que ver con las dinámicas migratorias vinculadas a los factores de atracción y expulsión que ejercen los ámbitos locales de forma específica. Estos factores estarían relacionados con la búsqueda de mayores oportunidades — de trabajo, vivienda, etc. - por parte de las familias y que se considera que ofrecen determinados municipios. Y, al contrario, se relacionarían con la percepción de la limitación de estas oportunidades, como factor explicativo de expulsión del territorio. Sin embargo, el asentamiento de nuevas familias inmigradas en el municipio fruto de la movilidad internacional no sería el único de los factores que vendría a explicar las variaciones de las cifras de la MV. En algunos casos, este incremento sería el resultado de los procesos de reagrupación familiar y la llegada de los hijos e hijas a Cataluña. Pero la MV también derivaría del reasentamiento en el territorio de familias inmigradas ya presentes en Cataluña y en el resto del Estado español y de los desplazamientos inter-

Gráfica 9. Proporción de alumnado MV sobre alumnado total en los doce municipios de la muestra. Curso 2009-2010

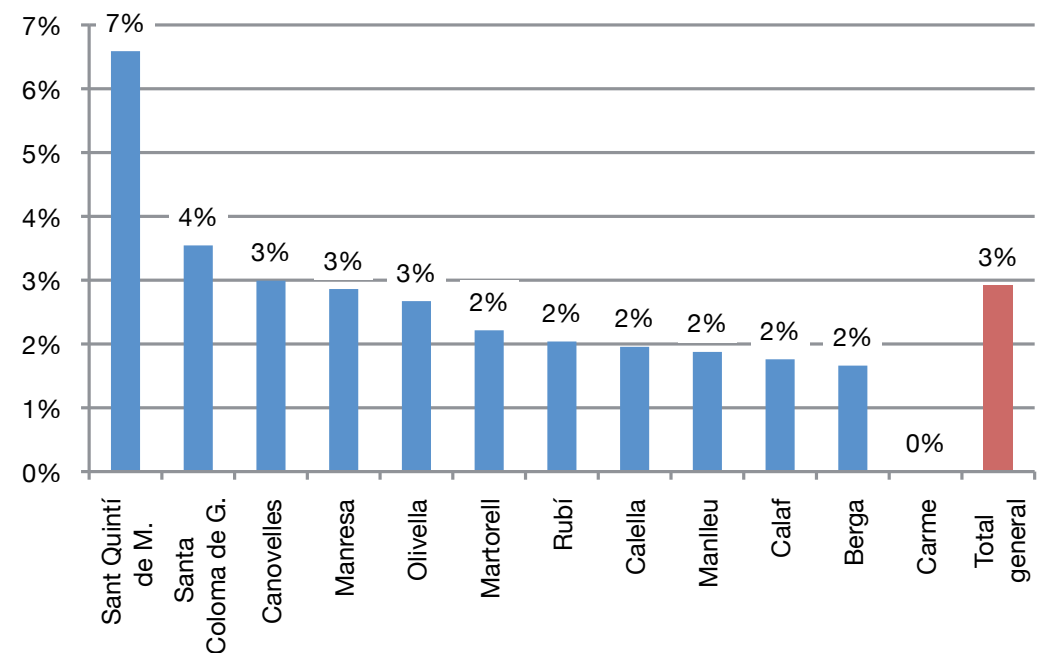

Fuente: elaboración propia a partir de los datos del Departament d’Educació de la Generalitat de Catalunya. 
nos de población protagonizado por familias de nacionalidad española. En ambos casos, las situaciones de ruptura familiar se convierten también en un factor explicativo creciente de esta movilidad, tanto en familias de origen autóctono como en familias inmigradas.

Para poder profundizar en estas dinámicas locales, a continuación nos centraremos en los resultados obtenidos en la fase intensiva y, en concreto, en las condiciones de escolarización desde el análisis de la gestión municipal. En este caso, prestaremos atención, tanto al papel que han desempeñado las oficinas municipales de escolarización (OME), como al de las comisiones de escolarización y los circuitos municipales que concurren en los procesos de adjudicación de las plazas escolares en el marco de la gestión de la movilidad y la escolarización de los niños y jóvenes.

\section{La gestión de la escolarización a nivel local: diversidad de respuestas y límites}

Del mismo modo que apuntábamos la inexistencia de unas tendencias de movilidad vinculadas al tamaño del municipio, en sentido inverso, la dimensión de los municipios resulta un factor esencial a la hora de gestionar los procesos de incorporación del alumnado de MV. Las características que adoptan las formas de gestión diferenciadas de estos procesos de incorporación en los diversos entes locales guardan una estrecha relación con características derivadas de las políticas educativas en Cataluña (mapa escolar, comisiones de garantías de admisión, oficinas municipales de escolarización, etc.) y con los procesos que emergen asociados a la movilidad del alumnado y de sus familias en cada entorno.

Por encima del reconocimiento de similitudes, las gestiones diferenciadas son deudoras, por una parte, de las dinámicas migratorias locales, pero también de las formas históricas de gestión en cada municipio de los procesos de matriculación e incorporación del nuevo alumnado en los centros y de la propia configuración del mercado educativo local. Sin embargo, en la gestión de estos procesos de incorporación, y bajo la óptica de las desigualdades, se apunta a las posibilidades diferenciales de acceso al mercado escolar por parte de las familias. Esto es así en la medida en que las instituciones educativas son potencialmente competidoras en la elección escolar que las familias hacen. El alcance de las políticas educativas en el marco de la legislación vigente y en el ámbito de los procesos de coresponsabilidad impulsados en Cataluña corren en paralelo a estas consideraciones, pero, por sí mismas, las formas diferenciadas de gestión que hemos podido identificar a lo largo de la investigación pueden ser también favorecidas por tendencias anteriores.

Los circuitos municipales para la escolarización del alumnado adoptan diversos grados de complejidad en los municipios observados. En municipios más pequeños, el circuito se ve bastante reducido, al existir en el territorio sólo una escuela y un instituto de secundaria. En estos municipios, los centros educativos se convierten en referentes locales para las familias, y las relaciones de proximidad favorecen los procesos de incorporación del alumnado de MV. La 
mayor parte de estos municipios no cuentan con los instrumentos de gestión y los dispositivos para la acogida municipal creados a tal efecto, como las oficinas municipales de escolarización (OME). Su no existencia, lejos de considerarse una dificultad, se valora de forma positiva, ya que la opinión generalizada es que se agilizan de este modo los procesos de incorporación del alumnado empadronado en el municipio:

Si tienes que pasar por una comisión de escolarización eso no te lo permite hacer porque tienes que tener los papeles mucho mejor [...] y yo si no me tiene la tarjeta sanitaria o no me tiene... no sé qué... me da igual, ya me la traerá [...] además la relación es: yo salgo fuera, los llamo y les hago entrar, no... (Municipio pequeño, centro educativo)

Además, en estos entornos, se despoja de sentido y atribuciones a la OME, y se asume que los niños y los jóvenes del municipio han de estar escolarizados en la escuela y en el instituto de la propia localidad. Esta valoración contrasta con los intentos que en algún momento ha habido para impulsar la creación de estos dispositivos, considerados forzados y que han puesto en evidencia, además, las resistencias de otras escuelas de municipios cercanos, que no compartían ciertas decisiones:

El año que comenzó la inspectora que esta escuela decidió que haría una OME, no sé qué $[\ldots]$ porque les dijo ella que los niños inmigrantes se repartían. A mí me llamaba el alcalde de [municipio cercano] a ver qué me había pensado yo de enviarle los niños inmigrantes hacia [municipio cercano]. Yo, todos los niños que hay en [municipio pequeño] son todos para mí, tanto como si me gusta como si no me gusta, si son NEE, como si son... Es que son míos y no tiene sentido, porque además, ¿el transporte quien lo pagará? No, es que aquí no, en [municipio mediano o grande] sí, pero aquí son todos para mí. Haya diez o haya veinte o haya cincuenta. (Municipio pequeño, centro educativo)

Esta proximidad, en especial la que se produce entre la escuela y las familias, hace que desde el mismo centro se gestionen los procesos de incorporación no sólo de los hijos e hijas en edad de escolarización en la etapa de primaria, sino también la incorporación de otros miembros de las unidades familiares en etapas educativas superiores. En este caso, se pone de manifiesto como, a partir de la confianza que las familias depositan en los representantes del centro, éste se convierte en un espacio de acogida y referente educativo local por encima de otros espacios municipales, que pueden ser percibidos por las familias como más burocráticos e incluso fiscalizadores:

A ver, yo aquí tengo una suerte o una desventaja, que yo me conozco las familias y las familias me conocen. Entonces, cuando [...] viene una familia que ya vivía aquí y me traen todos los pasaportes de la familia y yo hago la elección. A ver, este para mí, este para el instituto, éste ya si quieres algún módulo, algún PQPI porque éste ya tiene más de dieciséis años, les hago la elección [...] El ayuntamiento a veces da mucho miedo porque es un lugar de mayor control. 
(Municipio pequeño, centro educativo)

La proximidad con las familias y el conocimiento directo de la realidad del municipio hace que se puedan detectar con mayor facilidad las situaciones anómalas, como el absentismo escolar o el retraso en la matriculación de los niños:

Aquí ya nos conocemos [...] hay otro tipo de relación. Entonces me pueden venir: vendrá esta familia... A ver, los últimos que llegaron [...] tenían otra hermana y no iba al instituto. O sea, yo primero sabía que estaban aquí porque los había visto por la calle [...] dices: estos los quiero en el cole. «Oh, es que no, porque no tenemos libros...», "Tú llévalos al cole y ya lo solucionaremos, ya buscaremos con el asistente social, ya haremos lo que convenga [...], es casero pero funciona muy bien». (Municipio pequeño, centro educativo)

En estos municipios se flexibilizan los trámites burocráticos y se considera prioritaria la rápida incorporación de los niños en la escuela. También en los municipios medios se considera central, por encima de los requisitos de carácter administrativo, priorizar la incorporación de los niños y jóvenes a los centros:

Necesito tener un documento de identidad, sea el del padre, sea el de la madre, alguno, porque si no el ordenador no la acepta [...] primero haces la escolarización del niño [...] o es que no tiene el papel, no tiene el padrón, eso ya se soluciona $[. .$.$] . La verdad es que la ventaja de ser escuela única me permite$ hacer eso. (Municipio pequeño, centro educativo)

Yo, en el momento que informo, les digo que me vengan a ver con la documentación, básicamente para introducir bien los datos. Entonces, una vez has introducido datos, se pone en marcha el proceso de escolarización. ¿Que nos falta algo? Bueno, ya lo vamos haciendo poco a poco [...] Nos interesa que los chicos estén en la escuela lo antes posible [...] Y a partir de aquí, en una semana están escolarizados. (Municipio mediano, servicio educativo)

En municipios medios y grandes, las OME y las comisiones de escolarización han gestionado las incorporaciones. En los primeros, ha resultado más fácil agilizar estos procesos, tanto respecto a la distribución del alumnado en los centros como de los procedimientos y los circuitos que se siguen, en especial cuando el mapa escolar determinaba la existencia de una zona única de escolarización. Los profesionales entrevistados en estos municipios medianos manifiestan que la OME se creó con el objetivo de impulsar el trabajo en red y la búsqueda de mecanismos de entendimiento entre los agentes educativos de la localidad. Sus tareas se encuadraron en tres ejes: la atención personalizada a las familias, la agilización de los trámites de matriculación y la transparencia en los procesos de escolarización. El primero de estos ejes se desarrolla en tres niveles: información, asesoramiento y orientación y mediación. Desde la OME se da la información que se considera que las familias necesitan para poder hacer la elección del centro educativo para sus hijos e hijas: 
Y entonces aquí se le da toda la información del centro que quieren o si no tienen conocimiento del centro o de la ubicación y del talante. De las actividades que pueden encontrar en cada centro. (Municipio mediano, servicio educativo)

Los responsables de la OME señalan que las familias autóctonas de estos municipios conocen el sistema educativo, los centros escolares y su titularidad y deciden optar por un centro docente concreto. Así, se considera que en estos municipios las redes y los canales informales resultan primordiales en la elección que las familias hacen dentro del mercado educativo local:

Entonces es eso, también es un talante de pueblo, que el «boca oreja» funciona mucho aquí. (Municipio mediano, servicio educativo)

De forma inversa, existe la opinión generalizada de que las familias recién llegadas no tienen las mismas posibilidades de acceso a estas informaciones: desconocen el funcionamiento del sistema educativo, los circuitos de acogida y recursos de la ciudad y necesitan información y orientación sobre los centros escolares. La acogida a las familias recién llegadas que tienen hijos e hijas en edad escolar y llegan en periodo de MV sigue este circuito, que resulta similar al que existe en los grandes municipios:

Normalmente vienen al servicio de acogida, les informan de todos los recursos de la ciudad, tanto a nivel laboral como a nivel de servicios, y automáticamente pasan a la OME. Les explicamos un poco todo el funcionamiento, los centros que hay, qué harán en cada centro, donde están situados. (Municipio mediano, OME)

En este municipio, para alcanzar el tercero de los objetivos - la transparencia en los procesos de escolarización-, se potencia el traspaso de datos con los centros educativos. Y esta transparencia se ve potenciada por el impulso del trabajo conjunto con los centros:

Se trabaja muy conjuntamente con todas las escuelas. Hacemos reuniones de directores para trabajar proyectos comunes con el Ayuntamiento. Hacemos reuniones de AMPA de todos los centros para trabajar también cosas conjuntas. Quiero decir que tenemos bastante una tendencia a comunicar lo que se está haciendo en cada escuela. (Municipio mediano, servicio educativo)

En los municipios grandes, la creación de las OME no fue en muchos casos la primera de las iniciativas que se desarrollaron en el marco de la corresponsabilidad. Antes de la creación de las oficinas, ya existía un intenso trabajo entre los diversos agentes y servicios municipales y autonómicos a través del Consejo Escolar Municipal. Sin embargo, los resultados alcanzados han sido menores, como han puesto de relieve los datos obtenidos y también han señalado otras investigaciones. Pero en estos municipios es donde se ha generado a menudo más capacidad de reacción desde la provisión de recursos y prácticas que inten- 
tan agilizar los procesos de incorporación del alumnado, aunque ésta, de facto, se vea en última instancia dilatada en el tiempo por cuestiones que derivan de la propia idiosincrasia de los centros educativos y de sus gestores.

La creación de la OME marcó un punto de inflexión, pero sus actuaciones han venido condicionadas por la complejidad de la gestión que se deriva del tamaño de la localidad y, también en buena medida, por las limitaciones que impone la propia distribución de las zonas en la aplicación del mapa escolar. La oferta de plazas vacantes existentes en período de MV y las posibilidades de acceder a los centros están relacionadas, de forma especial, con el valor diferencial atribuido a las escuelas. En este sentido, la creación de la OME estuvo estrechamente vinculada a la voluntad de promover la llamada escolarización equilibrada desde la corresponsabilidad. Sin entrar aquí en la valoración de las iniciativas centradas en la lucha contra la segregación interescolar, los datos muestran que, en esta línea y respecto a la gestión de la MV, los avances han sido, cuanto menos, mediocres, a pesar de los intentos de impulsar medidas correctoras.

El hecho de que la adjudicación de plazas de MV esté condicionada por las vacantes existentes en los centros lleva a considerar que los resultados de la OME en relación con la escolarización equilibrada han sido poco exitosos. Como hemos visto, los datos señalan que, globalmente, el volumen de MV en los centros públicos es entre cuatro y cinco veces mayor que en los centros concertados. Ante esta situación, hay que distinguir algunas tendencias detectadas, ratificadas por las personas entrevistadas en los municipios y los centros:

1. La valoración que tienen los centros en el mercado educativo local depende de procesos históricos y de consideraciones actuales que las familias vinculan al prestigio y a la movilidad social. En estos procesos de selección y elección, los centros más deseados en periodo ordinario de matriculación disponen de menor oferta para poder incorporar el alumnado de MV.

2. La mayor presencia del alumnado extranjero y recién llegado en algunas escuelas no es resultado de su aumento en el período la MV, sino de la elección que las familias hacen en el proceso de matriculación ordinaria, a partir de la oferta y la propia configuración del mercado pedagógico en una doble red educativa como la actual.

3. La mayor estabilidad y continuidad entre etapas educativas dentro del mismo centro en la escuela privada concertada es un factor que frena la incorporación del alumnado en periodo de MV.

4. Los mecanismos articulados para llevar a cabo la escolarización equilibrada se debilitan ante el derecho a la elección de centro por parte de las familias en el periodo de MV.

5. Desde la perspectiva de la escolarización equilibrada, la no desagregación de datos por nacionalidades del alumnado invisibiliza los itinerarios diferenciados de incorporación a los centros de los niños y jóvenes extranjeros en periodo de MV. 
6. El aumento de ratio, ante la necesidad de ampliar la oferta educativa en los centros, ha sido una estrategia (controvertida y no generalizada) impulsada principalmente para dar respuesta al incremento de la MV.

En el análisis del fenómeno de la MV y su gestión desde el ámbito local, no se puede dejar de prestar atención a la percepción que tienen escuelas e institutos. El acercamiento a las instituciones educativas a pequeña escala nos permite, por un lado, considerar la valoración que éstas hacen de los procesos y de su gestión, pero también observar cómo se incorpora la gestión intraescolar del fenómeno y sus continuidades y discontinuidades en relación con los otros dispositivos y las otras instancias relacionadas.

En los municipios grandes, la mayor parte de los centros entrevistados consideran que la OME no ha logrado disminuir el impacto de la llegada de los niños y jóvenes de nueva incorporación en periodo de MV sobre unos centros por encima de otros, fundamentalmente porque su actuación depende de las posibilidades que le permite la zonificación escolar. Y a pesar de la valoración positiva que hacen del trabajo general de la oficina, desde los centros no se considera que haya corregido las desigualdades en el acceso a las escuelas de la ciudad, ni los desequilibrios preexistentes en las zonas educativas. Sin embargo, se prefiere que sea un órgano centralizado el que realice la recepción y la asignación de las plazas y se considera que es un instrumento democrático para la gestión de la MV. A pesar de esta valoración positiva, se considera que las relaciones con la OME podrían ser más fluidas. La complejidad de la ciudad hace que en las posibilidades de relación —así como las responsabilidades que los centros le atribuyen a la oficina- estén mediatizadas por la mayor o menor proximidad de las relaciones que se pueden tener con la inspección educativa:

Lo que pasa es que no siempre la relación es muy fluida. Y la OME ha pasado por etapas buenas y etapas no tan buenas. Hasta el año pasado, la presidenta de este organismo era nuestra inspectora, y a mí me venía muy bien, porque, como el contacto era directo, cualquier pequeña incidencia, cualquier pequeña duda la tenía resuelta enseguida. (Municipio grande, centro educativo)

En cambio, en los municipios medios y desde los centros públicos se considera que, con la creación de la OME, la escolarización equilibrada del alumnado de MV se ha podido mejorar:

Desde que está la OME, se reparten mejor los alumnos recién llegados en las escuelas. (Municipio mediano, centro educativo)

En realidad, en ambos contextos, los responsables municipales han realizado un trabajo dirigido a impulsar procesos colaborativos entre los centros educativos de titularidad pública y privada concertada — desde los planes educativos de entorno- buscando la implicación del conjunto de escuelas e institutos. Al tratarse de iniciativas que van más allá del ámbito de gestión de la 
MV, estas han tenido un cierto impacto, porque han permitido vencer resistencias iniciales a la implicación de ciertos centros en las nuevas realidades locales:

De los planes educativos de entorno, nosotros tomamos todas [...], incluidos institutos y una guardería. Entre ellas, una concertada, que está en el mismo barrio. [...] Lo que no era lógico que una escuela concertada no tuviera ningún alumno de inmigración y las otras dos estuvieran a reventar. A nosotros, la Comisión nos los enviaba hacia aquí. (Municipio grande, servicio educativo)

La resistencia de algunas escuelas privadas concertadas a la escolarización de los niños y jóvenes de MV se explicaba desde los centros por la falta de recursos externos. En este marco, los apoyos que han ido recibiendo han hecho disminuir las barreras iniciales que mostraban:

Y como hasta el 2005 las concertadas no tenían EAP, nos decían: «Nosotros no tenemos EAP». Ahora ellos tienen EAP, y tienen LIC, etc. (Municipio grande, servicio educativo)

Esta apreciación se corrobora con la valoración que se hace desde los centros públicos sobre los motivos de una incorporación superior de alumnado de MV en algunos centros más que en otros. Así, se considera que:

- Tener una mayor capacidad de los espacios incrementa las posibilidades de recibir el alumnado que proviene de MV:

Pero claro, eso ¿por qué es posible? Porque tienes sitio. Si no tienes sitio ya de entrada cierras la puerta. El hecho de tener mayor o menor capacidad ya nos condiciona a poder, en principio, poder tener más gente. (Municipio mediano, centro educativo)

- Tener vacantes y contar con una oferta más amplia incrementa las posibilidades de recibir el alumnado que proviene de la MV:

En función de las vacantes. La escuela que tiene vacantes pues van a parar allí, porque hay escuelas que son de una sola línea y están saturadas [...] las plazas que hay son las que hay. (Municipio mediano, centro educativo)

- Tener concedida un aula de acogida incrementa las posibilidades de recibir más alumnado de MV:

Por otra parte, también, hasta ahora habíamos sido nosotros los que habíamos tenido aula de acogida, entonces éramos, por decirlo así, más candidatos. (Municipio mediano, centro educativo)

El hecho de ser más grandes y por otro lado tener... No quiero decir más espacio, pero sí, de tener más grupos y de tener aula de acogida, pues siempre ha favorecido a que pudieran venir los recién llegados acá [...]. (Municipio mediano, centro educativo) 
En estos centros, se considera que la inspección educativa, con quien se mantiene una comunicación cercana, intenta suavizar la situación cuando se producen los procesos de incorporación del alumnado de MV:

A veces nos prepara, quiero decir, cuando viene alguien con un dictamen de esos que son a medio curso. Bueno, lo hace para que empieces a respirar y te prepares para saber si en un grupo o en otro. (Municipio mediano, centro educativo)

Ahora bien, tanto en los municipios medianos como en los grandes se considera que la OME es una especie de "árbitro" de la situación y que su existencia ha desvinculado a los centros de la gestión directa de los procesos de incorporación del alumnado:

A ver, el cambio es que antes te venían las familias al centro y tú tenías que coger todos los datos, entonces tenías que hablar con el inspector. La familia quizás elegía más el centro. Si había vacantes, claro, y en cambio desde que existe la OME ello se intenta repartir equitativamente entre comillas. (Municipio mediano, centro educativo)

También en estos municipios los centros consideran que la comunicación con la OME es fluida. Esta se realiza vía telefónica o por correo electrónico, pero la valoración cambia al centrarnos en el papel de la Comisión de Escolarización. Las personas entrevistadas opinan que, a pesar de ser un buen instrumento y desarrollar de forma correcta las funciones que le son encomendadas, esta Comisión debería ser un órgano donde los agentes educativos tuvieran un papel más activo:

Cuando iban a las comisiones de escolarización, es que prácticamente no tenían ningún poder de decisión, ya venía todo hecho y aderezado [...] quien lo llevaba... El inspector o desde la OME, estaba todo resuelto, simplemente informaban. (Municipio mediano, centro educativo)

\section{Recapitulando: Movilidad del alumnado, corresponsabilidad $y$ derechos educativos}

Para complementar la comprensión de las tendencias de la MV en Cataluña y las condiciones existentes para la escolarización de los niños y jóvenes que se incorporan a los centros escolares a lo largo del curso académico, desde el análisis de la gestión municipal, procederemos a detallar algunas de las consideraciones que se desprenden del análisis de los resultados del estudio.

En primer lugar, se confirman algunas percepciones previas y vigentes sobre las tendencias de la movilidad del alumnado, pero se matizan y se cuestionan otras. Por ejemplo, el volumen de MV de los centros públicos es entre cuatro y cinco veces mayor que el de los centros concertados, y esta proporción no se corresponde con la distribución del alumnado escolarizado por titularidad. 
En el curso 2009-2010, mientras el alumnado escolarizado era el 64\% en la escuela pública y el $36 \%$ en la concertada, la proporción de MV fue de $82 \%$ en la pública y $18 \%$ en la concertada. Esta desproporción se debe básicamente a dos factores: por un lado, la existencia de un mayor número de vacantes en la escuela pública después del período ordinario de matrícula; por otro, la existencia de una mayor estabilidad y continuidad entre etapas educativas dentro del mismo centro en la escuela concertada, que, entre otros factores, reduce considerablemente la disponibilidad de plazas. Ahora bien, el análisis de las realidades locales pone de relieve que el fenómeno de la movilidad del alumnado tiene impactos muy diversos en los centros: en algunos centros públicos la movilidad es irrelevante, mientras que en algunos centros concertados se detectan niveles de movilidad más elevados.

En segundo lugar, el estudio ha permitido constatar que, a pesar de la percepción generalizada de que la mayor parte del alumnado de nacionalidad extranjera llega a lo largo del curso académico produciendo una situación difícil de gestionar, la movilidad del alumnado sigue patrones diferenciados que no coinciden con las tendencias seguidas por el alumnado de nacionalidad española o extranjera. Destaca el hecho de que, tanto en el conjunto de Cataluña como en la provincia de Barcelona, alrededor del $40 \%$ de la MV corresponde a alumnado de nacionalidad española. En algunos casos, como el de las familias procedentes de Pakistán, República Dominicana y Colombia, la movilidad de alumnos por MV corresponde principalmente a llegadas directamente del extranjero, mientras que, entre otras nacionalidades, se observan patrones de movilidad muy similares a las de la movilidad del alumnado de nacionalidad española. Este es el caso del alumnado de nacionalidad marroquí, cuya movilidad corresponde sólo en el $41 \%$ de los casos a llegadas de fuera del Estado, o del alumnado de nacionalidad rumana, perteneciente a un flujo migratorio mucho más reciente, con sólo la mitad (50\%) de incorporaciones de MV procedentes de fuera del Estado. En ambos casos, se observa una diversidad mayor de motivos para cambiar de centro, como en el caso del alumnado de nacionalidad española. También es el caso del alumnado de nacionalidad ecuatoriana: en el 55\% de los casos, su movilidad corresponde a incorporaciones de fuera del Estado, provienen en un 10\% de la propia comunidad autónoma y en un 9\% del resto del Estado. El resto de motivos se aglutinan dentro de las categorías que constatarían aquel patrón de movilidad dentro de una red urbana e interurbana en distancias cortas señalado por otros estudios realizados en el Reino Unido y en los EEUU.

La movilidad de las familias de nacionalidad española y extranjera puede seguir patrones similares, vinculados a los factores de atracción y expulsión que ejercen los entornos locales de forma específica en relación con las oportunidades del entorno. Los resultados permiten inferir, a través de los testimonios de responsables de la Administración local y de los equipos directivos de los centros entrevistados, que entre estos factores de atracción y expulsión relacionados con la movilidad del alumnado fuera del periodo ordinario de matrícula, se encuentra de forma prioritaria la búsqueda de oportunidades 
laborales de las familias, el acceso a una vivienda más barata y, más recientemente, con cambios de barrio y de centro provocados por desahucios. En cambio, la búsqueda de ofertas educativas consideradas mejores resulta ser un factor menos relevante hasta ahora en Cataluña, mientras que los datos muestran claramente que la reagrupación familiar explica sólo una pequeña parte de las nuevas incorporaciones, que han tenido episodios de alta intensidad entre 2007 y 2009, coincidiendo con el cambio de ciclo económico. Por último, las situaciones de ruptura familiar se convierten también en una causa creciente de esta movilidad, tanto en el caso del alumnado de nacionalidad española como en el alumnado de nacionalidades extranjeras.

Por otra parte, desde la perspectiva de la gestión, podemos concluir que los sistemas de corresponsabilidad impulsados desde el gobierno autonómico en los dos últimos periodos progresistas ${ }^{6}$, a pesar de los esfuerzos legislativos realizados, no han conseguido alcanzar los objetivos previstos en la gestión compartida de los procesos de incorporación escolar del alumnado de MV entre las diferentes administraciones. En concreto:

- Aunque existe una confusión generalizada entre la idea de escolarización equilibrada y el significado real de la equidad educativa, los procesos de asignación de plazas para el alumnado de MV tampoco permiten realmente aplicar los criterios que teóricamente la fundamentan.

— La condición de extranjero se impone globalmente por encima de otras más precisas, como los orígenes nacionales, a la hora de implementar los procesos de escolarización equilibrada del alumnado en los centros, de manera que se acaba reforzando la asociación —inexacta— de la nacionalidad a la movilidad por MV.

- El tamaño de los municipios resulta esencial a la hora de agilizar los procesos de incorporación del alumnado en los centros cuando llega fuera del periodo de matrícula ordinaria.

- En municipios pequeños, los centros educativos se convierten en referentes para las familias y las relaciones de proximidad favorecen los procesos de incorporación del alumnado de MV. En municipios medios y grandes, los dispositivos para la acogida, como las oficinas municipales de escolarización (OME), han gestionado las incorporaciones.

- En los municipios pequeños y medianos, resulta más fácil agilizar los procesos de incorporación, tanto respecto a la distribución del alumnado en los centros como de los procedimientos y los circuitos que se siguen, en especial cuando el mapa escolar determina la existencia de una zona única de escolarización.

- En los municipios de dimensiones mayores, aunque es donde se ha generado más capacidad de reacción ante la llegada de alumnado de MV, de facto, la incorporación de este alumnado a los centros se ve a menudo dilatada en

6. Gobiernos de coalición de la Generalitat de Catalunya formados por PSC, ERC e ICV en dos legislaturas sucesivas (2003-2006 y 2006-2010). 
el tiempo por cuestiones que derivan de la gestión y la idiosincrasia de los propios centros educativos, más que de la Administración local.

Finalmente, es necesario prestar atención al impacto de las diferencias locales en la gestión de la movilidad del alumnado desde la perspectiva de los derechos educativos. Algunos ejemplos de administraciones locales y comarcales coordinadas, en municipios medianos y también por parte de algunos centros de los municipios de mayor tamaño, han previsto la reserva de algunos recursos de acompañamiento a la escolaridad (fundamentalmente, las becas de comedor), para poder atender al alumnado que se incorpora a lo largo del curso académico a centros ubicados en territorios de su competencia, pero el estudio ha constatado que esta práctica es todavía muy minoritaria y no existen orientaciones generales al respecto.

\section{Una reflexión final}

El estudio ha permitido empezar a delimitar el fenómeno de la movilidad del alumnado y los factores derivados de la misma, y también de su gestión a diferentes niveles, que contribuyen a configurar condiciones de escolarización diferenciada tanto para el alumnado que se mueve, como para el alumnado que permanece estable en los centros, entre los sectores sociales más desfavorecidos. Sin embargo, resulta necesario seguir profundizando en esta línea de investigación para conocer las dinámicas de la movilidad en áreas diversas de Cataluña con características territoriales, poblacionales y educativas específicas, así como el funcionamiento de la cogestión en la escolarización a nivel local y sus constreñimientos a pesar del supuesto desarrollo de los procesos de descentralización territorial y subsidiariedad de los procedimientos y los dispositivos presentes en los municipios. De igual modo, resulta imprescindible abordar el estudio de la organización escolar y las trayectorias académicas del alumnado afectado por la movilidad. Esto es especialmente necesario en un contexto que entiende la movilidad preuniversitaria como una anomalía y un riesgo, aparentemente sin respuestas que puedan evitar sus efectos negativos, mientras propugna la movilidad de aquellos que logran desarrollar trayectorias académicas de mayor duración, entendiendo, entonces, paradójicamente, que el esfuerzo adaptativo y el conocimiento de diversos entornos constituye un aprendizaje positivo en sí mismo.

Por otra parte, es indudable que, ante las dinámicas de alta movilidad del alumnado, recae sobre el profesorado la necesidad de responder con flexibilidad a las necesidades de los diferentes alumnos que se van incorporando, adaptar contenidos y mantener al mismo tiempo el progreso en el conocimiento de todo el alumnado. Esto no es fácil y también debe tenerse en cuenta el impacto de la movilidad en los alumnos que no se mueven, porque pueden experimentar, asimismo, rupturas en las relaciones, repeticiones de contenidos y cambios más frecuentes en la planificación curricular. A pesar de ello, es el alumnado que se mueve el más afectado, porque necesita desarrollar habilidades que le 
permitan hacer frente a la inestabilidad y establecer nuevas relaciones de confianza con sus pares y con los adultos en el nuevo centro ${ }^{7}$. Una experiencia de movilidad reiterada puede tener efectos sobre el bienestar psicológico derivado de las rutinas infantiles, sobre el seguimiento de su salud física, de sus relaciones y aprendizajes, etc., y muy especialmente porque la movilidad del alumnado tiene lugar muchas veces en contextos de dificultades familiares y puede constituir un buen indicador de otros riesgos a los cuales están expuestos niños y jóvenes, como la pobreza o la violencia.

Y precisamente por estas razones resulta imprescindible impedir que aquellos niños y jóvenes que se ven afectados por la movilidad en primera instancia sean percibidos como elementos negativos que vienen a impactar en la vida ordinaria de las escuelas, en lugar de prestar atención a las situaciones que pueden estar viviendo desde la perspectiva de los derechos educativos y sociales que les deberían asistir y que se pueden ver vulnerados o desatendidos según como se lleve a cabo la gestión de la movilidad del alumnado en los municipios y en los centros educativos. Además, si bien podemos afirmar que, a la hora de investigar la movilidad, hay que tener en cuenta que se trata de «un objetivo móvil» en sí mismo, con causas y efectos diferentes en distintas circunstancias y periodos, como también subrayan Guy y Takanishi (2010): «es muy importante tener un mejor conocimiento de la movilidad y sus efectos porque la mayoría de intervenciones dirigidas a los niños y jóvenes más vulnerables todavía están basadas y pensadas desde la idea de permanencia en un mismo lugar». Investigar la movilidad del alumnado exige, pues, superar las percepciones derivadas de la perspectiva receptora e institucional dominante, para situarla más allá de la definición del fenómeno como «matrícula viva», a fin de recuperar la centralidad de los sujetos y los procesos sociales.

\section{Referencias bibliográficas}

AADD (2010). Estudi sobre la «matrícula viva» als municipis de la provincia de Barcelona. Área d'Educació de la Diputació de Barcelona (documento interno elaborado por S. Carrasco, J. Pàmies, B.A. Bereményi y V. Casalta 217 p.).

Association of London Government (2005). Breaking Point: Examining the disruption caused by pupil mobility [en línea]. Londres: Association of London Government.

$<$ http://www.londoncouncils.gov.uk/upload/public/attachments/474/ALG_mobility_report_final.pdfs

7. En este sentido, debemos señalar la ausencia de investigaciones sobre la movilidad del profesorado y su impacto en la capacidad de los centros educativos para crear condiciones y experiencias de continuidad, coordinación y referencia para el alumnado, las familias y los entornos en los que desarrollan su tarea. A menudo, como se ha podido observar en el trabajo de campo, los centros y los barrios afectados por mayores niveles de movilidad del alumnado también son aquellos con mayor inestabilidad de una plantilla que pueda ofrecer respuestas organizativas y relacionales adecuadas y sostenidas, aunque esta cuestión requerirá investigaciones específicas. 
Bonal, X. (2006). L'estat de l'educació a Catalunya. Barcelona: Ed. Mediterrània i Fundació Jaume Bofill.

Bonal, X.; Gonzalez, I. y Valiente, O. (2005). Les noves Oficines Municipals d'Escolarització: valoració d'experiències i propostes de disseny. Document de treball. Diputació de Barcelona. Àrea d'Educació.

CARRASCO, S. (dir.) (2003). Immigració i diversitat sociocultural a les escoles de Barcelona. Estudi sobre l'origen sociocultural $i$ la concentració escolar als centres públics municipals $i$ de Ciutat Vella. Barcelona: Ajuntament de Barcelona. Observatori Barcelona. Estudis/Monografies, 1.

CARrasCO, S. (2008). «Segregació i immigració: repensant plantejaments i alternatives». Nous Horitzons, 190, 31-40.

CARrasco, S. y PÀMIES, J. et al. (2009). «Segregación escolar e inmigración en Cataluña: aproximaciones etnográficas». Emigra Working Papers [en línea], 126. <http:// grupsderecerca.uab.cat/emigra/content/emigra-working-papers-4>

COle-HendersOn, B. (2000). "Organizational characteristics of schools that successfully serve low-income urban African American students». Journal of Education for Students Placed at Risk, 5 (1, 2), 77-91.

CROWLEY, S. (2003). «The affordable housing crisis: residential mobility of poor families and school mobility of poor children». Journal of Negro Education, 72 (1), 22-38.

Dobson, J.; Henthorne, K. y Lynas, Z. (2000). Pupil mobility in schools: Final report. London: Migration Research Unit.

Fantuzzo, J.; Rouse, H. y LeBoeuf, W. (2009). Homelessness, School Mobility, and Educational Well-Being in a Large Urban School System. Presentación del Workshop on the Impact of Mobility and Change on the Lives of Young Children, Schools, and Neighborhoods, 29 y 30 de junio. Washington, DC: The National Academies. <http://www.bocyf.org/fantuzzo_rouse_presentation.pdf> [Consulta: març 2010].

Gibbons, S. y Telhaj, S. (2007). Mobility and school disruption. CEEDP, 83. Centre for the Economics of Education, London

Guy, D. y TAKanishi, R. (2010). Presentation, in Rumberger, R.W. y Beatty, A. (cords.) Student Mobility: Exploring the Impact of Frequent Moves on Achievement: Summary of a Workshop. The National Academies Press.

HanusheK, Eric A.; Kain, John F. y Rivkin, Steven G. (2004). «Disruption versus Thiebout improvement: The costs and benefits of switching schools». Journal of Public Economics, 88 (9), 1721-1746.

Machin, S. y Telhaj, S. et al. (2006). "The mobility of English school children». Fiscal Studies, 27 (3), 253-280.

NAKAGAWA, K.; STAFFORD, M.E. et al. (2002). "The "city migrant" dilemma: Building community at high-mobility urban schools». Urban Education, 37 (1), 96-125.

Office for Standards in Education (2002). Managing Pupil Mobility. Londres: OFSTED.

Reynolds, A.J.; Chen, C.-C. y Herbers, J.E. (2009). School Mobility and Educational Success: A Research Synthesis and Evidence on Prevention [en línea]. Comunicación presentada en el Workshop on the Impact of Mobility and Change on the Lives of Young Children, Schools, and Neighborhoods, 29 y 30 de junio. Washington, DC: The National Academies. <http://www.bocyf.org/children_who_movereynolds_paper.pdf>

Rhodes, V. (2007). «Student mobility: The elephant in NCLB's living room». ERS Spectrum, 25 (1), 1-10. 
Rumberger, R.W. (2003). «The causes and consequences of student mobility». Journal of Negro Education, 72 (1), 6-21.

Rumberger, R.W. y Beatty, A. (coords.) (2010). Student Mobility: Exploring the Impact of Frequent Moves on Achievement: Summary of a Workshop. The National Academies Press.

Sampson, R.J.; Graif, C.; Owens, A. y Sharkey, P. (2009). Patterns and Structure of NeighborhoodMobility Among Families in Chicago [en línea]. Presentación del Workshop on the Impact of Mobility and Change on the Lives of Young Children, Schools, and Neighborhoods, 29 y 30 de junio. Washington, DC: The National Academies. <http://www.bocyf. org/sampson_presentation.pdf>.

ScHAFFT, K.A. (2003). Low-Income Student Transiency and Its Effects on Schools and School Districts in Upstate New York. Comunicación presentada en el simposio Promoting the Economic and Social Vitality of Rural America: The Role of Education. Nueva Orleans, LA, 14 y 15 de abril.

- (2006). "Poverty, residential mobility, and student transiency within a rural New York school district». Rural Sociology, 71 (2), 212-231.

SchaffT, K.A.; KilleEn, K. y Morrissey, J. (2010). "The challenges of student transiency for U.S. rural schools and communities in the era of No Child Left Behind». En: SCHAFFT, K.A. y JaCKSOn, A. (eds.). Rural Education for the Twenty-First Century: Identity, Place, and Community in a Globalizing World. University Park: Pennsylvania State University Press. Rural Studies Series.

Schwartz, A.E.; Stiefel, L. y Chalico, L. (2009). The Multiple Dimensions of Student Mobility: Evidence from NYC [en línea]. Presentación del Workshop on the Impact of Mobility and Change on the Lives of Young Children, Schools, and Neighborhoods, 29 y 30 de junio. Washington, DC: The National Academies. <http://www.bocyf.org/schwartzpresentation.Pdf>.

Strand, S. y Demie, F. (2006). "Pupil mobility, attainment and progress in primary school». British Educational Research Journal, 32 (4), 551-568.

- (2007). «Pupil mobility, attainment and progress in secondary school». Educational Studies, 33 (3), 313-331.

TuCKer, C.J.; MARX, J. et al. (1998). «Moving on: Residential mobility and children's school lives». Sociology of Education, 71 (2), 111-129.

UnIVERSITY OF THE STATE OF NEW YORK (1992). Student and Teacher Mobility: Impact on School Performance in New York City Public Schools. Albany: State Education Department. Office for Planning. Research and Support Services. 